\title{
Novel biodegradable polydioxanone stents in a rabbit airway model
}

\author{
Ladislav Novotny, DVM, PhD, MRCVS, ${ }^{\mathrm{a}}$ Michal Crha, DVM, PhD, ${ }^{\mathrm{b}}$ Petr Rauser, DVM, PhD, ${ }^{\mathrm{b}}$ \\ Ales Hep, MD, ${ }^{\mathrm{c}}$ Jan Misik, MSc, ${ }^{\mathrm{d}}$ Alois Necas, DVM, PhD, ${ }^{\mathrm{b}}$ and David Vondrys, MD, FRCS
}

Objective: This study was undertaken to evaluate safety and biocompatibility of a novel biodegradable polydioxanone stent in a rabbit tracheal model. Metallic and silicone stents represent standard therapeutic approaches for hollow organ stenosis, although complications have been reported repeatedly. Biodegradable stents could reduce the risks associated with this procedure while still achieving the purpose of maintaining lumen patency.

\begin{abstract}
Methods: A commercially available polydioxanone suture strand with a long safety record was used to manufacture the self-expanding stents. The polydioxanone stents were then implanted bronchoscopically and under fluoroscopic guidance into the tracheas of white rabbits $(\mathrm{N}=25)$. Periodic clinical examination was performed. Histopathologic examination concluded the study for the 5 experimental groups at 3, 4, 5, 10, and 15 weeks after implantation.

Results: There were no unexpected deaths and no stent displacements during the study. The animals remained in good condition, without stent debris expectoration. Macroscopic examination revealed that the tracheal lumen stayed open. Histologic examination showed that tracheal damage score was highest 5 weeks after stenting, including in-stent necrosis of the epithelium. Stent degradation was complete with no remnants after 10 weeks, leaving the trachea completely healed at 15 weeks after implantation.

Conclusions: This animal airway model has demonstrated acceptable safety and biocompatibility of this novel biodegradable polydioxanone stent. We suggest that polydioxanone stenting be used for further clinical studies for cases in which complete stent degradation after temporary airway treatment is desirable. (J Thorac Cardiovasc Surg 2012;143:437-44)
\end{abstract}

Stenting is an important therapeutic modality for the maintenance of lumen patency in different tubular organs. For airways, there are 4 categories of stent currently available: silicone stents, balloon-dilated metal stents, selfexpanding metal stents, and hybrid silicone and metal stents (covered self-expanding metal stents). ${ }^{1}$ Silicone stents tend to migrate and disturb airway mucociliary clearance. Metallic stents cannot be removed once embedded in the wall, and they pose the risk of a secondary stenosis as a result of hyperplastic granulation. ${ }^{2}$ In children with severe tracheobronchomalacia or vascular compression, stenting presents

From the Institute of Pathology and Parasitology ${ }^{a}$ and Department of Surgery and Orthopaedics, ${ }^{\mathrm{b}}$ University of Veterinary and Pharmaceutical Sciences Brno, Brno, Czech Republic; the Endoscopic Clinic of the University Hospital Brno, ${ }^{\mathrm{c}}$ Brno, Czech Republic; the Department of Toxicology, ${ }^{\mathrm{d}}$ Faculty of Military Health Sciences, University of Defence, Hradec Králové, Czech Republic; and Great Ormond Street Hospital, ${ }^{\mathrm{e}}$ London, United Kingdom.

This experimental study is a part of a larger research project of M.C. It was cofinanced by the European Social Fund and the State Budget of the Czech Republic, project No. CZ.1.07/2.3.00/09.0193, and was also supported by the research project No. MSM 0021620820.

Disclosures: Authors have nothing to disclose with regard to commercial support.

Received for publication May 18, 2011; revisions received July 19, 2011; accepted for publication Aug 2, 2011; available ahead of print Sept 1, 2011

Address for reprints: David Vondrys, MD, FRCS, Tracheal Team, Great Ormond Street Hospital, Great Ormond Street, WC13NH, London, UK (E-mail: david@ vondrys.com).

$0022-5223 / \$ 36.00$

Copyright (c) 2012 by The American Association for Thoracic Surgery

doi:10.1016/j.jtcvs.2011.08.002 an unacceptable risk because of the previously mentioned erosion by these metal and plastic frameworks. ${ }^{3}$

To avoid the mechanical complications associated with nonabsorbable stents, many groups have focused on the development of absorbable stents. Currently, there are a few bioabsorbable and biodegradable materials available for construction of such stents, such as poly-L-lactic acid, polyglycolic acid, polycaprolactone, poly(lactic-co-glycolic acid), and polydioxanone. ${ }^{4}$ Polydioxanone (poly-p-dioxanone) is a monofilament, absorbable material widely used as a suture in soft tissue surgery. ${ }^{5}$ It is a biodegradable, semicrystalline polymer belonging to the polyester group. Its monofilament has a degree of "shape memory" and tends to coil. It degrades by random hydrolysis of its molecular ester bonds. Degradation accelerates at low pH. All degradation products and their intermediates are harmless. The degradation process occurs in 2 stages. The first involves amorphous regions of the matrix, the second the crystalline areas of the polymer. Because mechanical and physical properties depend much on the presence of the crystalline areas, the mechanical effect of degradation is not linear. ${ }^{6}$

Biodegradable stents have already been developed for esophageal, intestinal, urethral, biliary duct, and vascular stenoses. ${ }^{7-10}$ Various biodegradable materials have been used experimentally for stenting of tracheobronchial stenosis since $1998 .{ }^{11-14}$ The first results of polydioxanone 


\section{Abbreviation and Acronym \\ TDS $=$ tracheal damage score}

airway stents in patients with bronchial stenosis after lung transplant have recently been published,${ }^{15}$ but the degradation time of polydioxanone stents in the trachea or bronchi remains to be defined. These stents have, however, been shown to be well tolerated by tracheal mucosa, to maintain biomechanical strength for as long as 6 weeks, and to dissolve completely by 15 weeks. ${ }^{16}$ Ongoing animal studies should further clarify the efficacy and safety of polydioxanone airway stenting. The stent material in this anatomic localization is hypothetically partly absorbed and partly expectorated. The main goals of our experiment were to identify a tissue reaction to the polydioxanone stent in the rabbit trachea and to estimate the degradation time of such stents.

\section{MATERIALS AND METHODS}

\section{Stents and Implantation Technique}

The braided stents had a diameter of $6 \mathrm{~mm}$ and a length of $30 \mathrm{~mm}$ (Figure 1,A) and were manufactured (ELLA-CS sro, Hradec Kralove, Czech Republic) from commercially available polydioxanone monofilament (Samyang Co, Seoul, Korea) of 0.340 to $0.399 \mathrm{~mm}$ (EP3) in diameter. Currently, only esophageal biodegradable stents of a larger caliber are commercially available from the same manufacturer. A $6-\mathrm{mm}$ diameter was chosen for the stent because it was approximately $15 \%$ larger than the normal physiologic diameter of the rabbit trachea, which measures $4.71 \mathrm{~mm}$ in its ventral-dorsal diameter and $5.92 \mathrm{~mm}$ in its lateral diameter with an average length of 55 to $58 \mathrm{~mm}$ in animals with a body weight of 3.00 to $3.50 \mathrm{~kg} .{ }^{17}$

The stent was fitted with radiopaque markers at each end. The sterilized stent was delivered in an airtight container, which was opened immediately before implantation to minimize stent degradation by humidity. The stent was loaded manually into the delivery system $(12 \mathrm{~F}, 4 \mathrm{~mm}$ in outer diameter and $40 \mathrm{~cm}$ in active length), which was composed of a hollow plastic guiding tube with an olive tip designed to accept a 0.89 - $\mathrm{mm}(0.035$-inch) guidewire and an overtube (Figure 1,B).

As it is loaded into the delivery system, the stent elongates. To establish mechanical deformation resistance during stent elongation, a local compression test was carried out by the manufacturer. The eccentric localized (point) load method ${ }^{18}$ was chosen for different constrictions and elongations of the $12 \times 40$-mm stent. Stress as a measure of force per unit area was expressed in grams per square centimeter. The stress necessary to collapse the diameter of the stent to $50 \%$ of its pretest diameter was established.

The in vitro degradation of polydioxanone by hydrolysis had been examined previously in the manufacturer's laboratories. In these tests, polydioxanone stents ("dog bone" configuration $23 \mathrm{~mm} \times 18 \mathrm{~mm} \times$ $23 \mathrm{~mm} \times 60 \mathrm{~mm}$ ) were immersed in phosphate-buffered normal saline solution at $37^{\circ} \mathrm{C}$, and the reduction in radial resistive force was examined serially for 12 weeks.

\section{Animal Study}

All animals received humane care in accordance with the "Principles of Laboratory Animal Care" formulated by the National Society for Medical Research and the Guide for the Care and Use of Laboratory Animals" (www.nap.edu/catalog/5140.html) prepared by the Institute of Laboratory Animal Resources, National Research Council, and published by the National Academy Press, revised in 1996. All experiments were performed with the permission of and under the supervision of the ethics committee of the Faculty of Military Health Sciences (Hradec Králové, Czech Republic).

Thirty White New Zealand 10-month-old female rabbits with average weight of $3.2 \mathrm{~kg}$ were allotted to 6 groups of 5. Five groups were used for implantation of the intratracheal stent, and 1 group was an untreated control group. Animals were placed in the Animal House of the Faculty of Military Health Sciences of The Czech University of Defence. Rabbits were fed unrestrictedly, with all-day access to water. Rabbits were kept in separate cages in isolated room with the temperature $20^{\circ} \mathrm{C}$ and humidity $50 \%$ with 12 -hour light cycles.

For stent implantation, the rabbits were anesthetized with xylazine ( $3 \mathrm{mg} / \mathrm{kg}$ intramuscularly) and ketamine ( $30 \mathrm{mg} / \mathrm{kg}$ intramuscularly). This was followed by anesthesia prolongation with the same agents $(50 \%$ of initial doses every 20 minutes) through an intravenous cannula placed into the aural lateral vein. The animals breathed spontaneously during the operation, with oxygen supplementation by endoscope during the time of the stent implantation. All animals were examined by fluoroscopy and bronchoscopy before stent implantation. The diameter of the tracheal lumen was measured, and the polydioxanone stent was delivered to the middle trachea with the delivery system under fluoroscopic guidance with the aid of a guidewire. After placement of the stent, its position and expansion in the tracheal lumen were examined by bronchoscopy and fluoroscopy (Figure 1, $C$ and $D$ ). Bronchoscopy was also performed every 4 weeks and immediately before histopathologic examination (Fujinon Video Processor, EPX-4400HD, and flexible videobronchoscope Fujinon EB-470P, diameter $3.8 \mathrm{~mm}$ and length $60 \mathrm{~mm}$; Fujinon, Osaka, Japan). The animals were anesthetized for bronchoscopies with intramuscular injections of medetomidine hydrochloride (INN medetomidine, $0.25 \mathrm{mg} / \mathrm{kg}$ ) and ketamine $(30 \mathrm{mg} / \mathrm{kg})$.

The animals were clinically observed daily, and any respiratory distress was recorded. We have used the following grading of respiratory distress: normal, respiration without stridor with normal rate; mild distress, intermittent stridor on exertion only, with normal appetite and intake of water; moderate distress, intermittent stridor also in rest, mostly inspiratory, increased respiration rate, increased intake of water, and some nasal watery discharge; and severe distress, continuous inspiratory and expiratory stridor, rich mucopurulent nasal discharge, overall labored respiration, higher intake of water, and decreased appetite.

Finally, the animals were killed at 3, 4, 5, 10, and 15 weeks after stent implantation (groups W3, W4, W5, W10, and W15, respectively) with intravenous injection of T61 (200 mg embutramide, $50 \mathrm{mg}$ mebozonium iodide, and $5 \mathrm{mg}$ tetracaine hydrochloride) at a dose of $0.3 \mathrm{~mL} / \mathrm{kg}$. Complete histopathologic examination followed. Rabbits in the control group were killed along with animals in the last group (15 weeks after implantation in the experimental groups). The whole trachea, including the stented area, was collected and immersed in buffered $10 \%$ formalin for histopathologic study.

\section{Histopathologic Analysis}

Tracheal samples were fixed in $10 \%$ buffered formalin and processed with the standard histologic paraffin technique with staining by hematoxylin and eosin. Slides were observed with an optical microscope (Olympus BX 51; Olympus, Aomori, Japan) with a digital output (Olympus DP 71 camera).

\section{Semiquantitative Analysis of Tracheal Tissue Reaction}

The type and degree of tissue reaction severity, including the amount of inflammatory cells in the tissue samples, were assessed in 6 randomly selected microscopic view fields from each animal at high power 

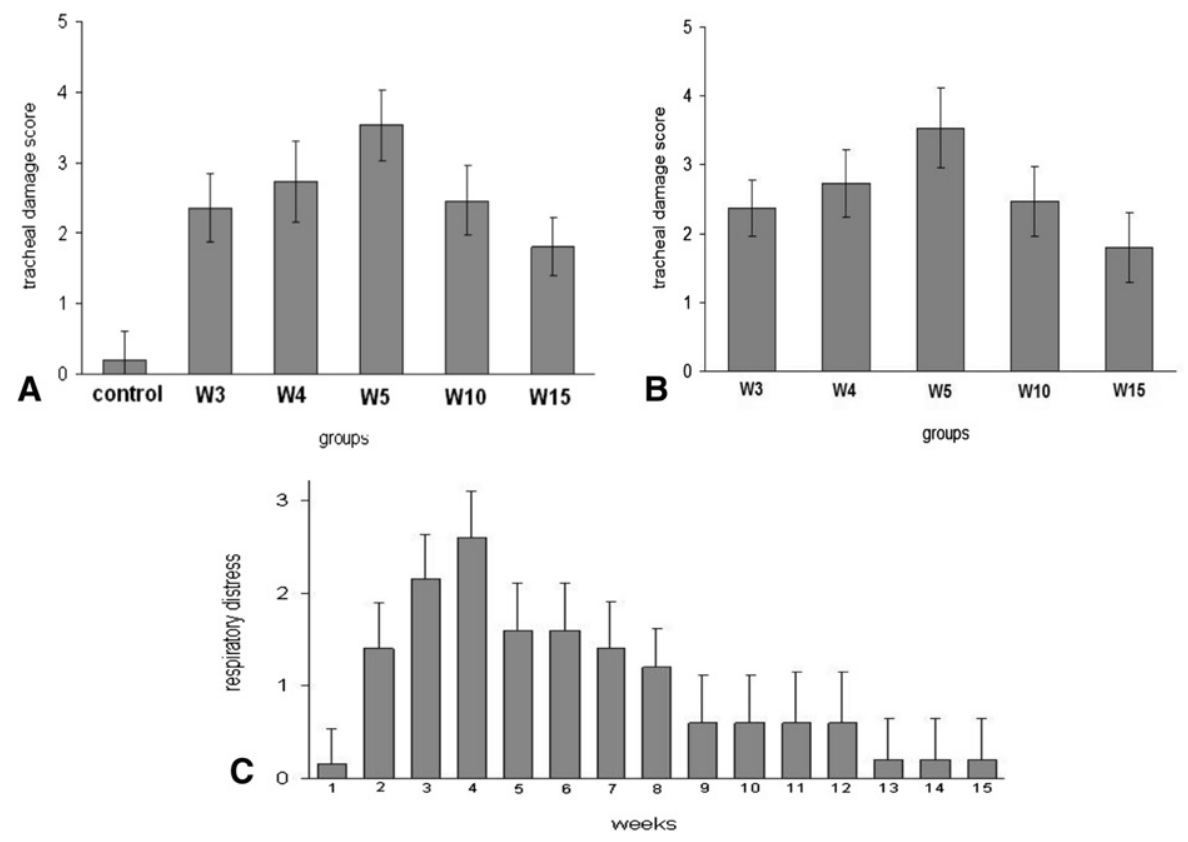

FIGURE 1. A, Graphic evaluation of statistically significant differences between control group and all experimental groups (Mann-Whitney U test, all $P<.009)$ in tracheal damage score. B, Graphic evaluation of statistically significant differences in tracheal damage score between experimental groups. (Mann-Whitney U test, all $P<.009$ ). C, Graphic evaluation of statistically significant differences in respiratory distress in all animals week by week (Mann-Whitney U test, weeks $2-8, P<.009$ ).

( $\times 40$ objective). The severity of tissue lesions was graded with a tracheal damage score (TDS) scale of 0 to 5, according to the degree of cellular degeneration, necrosis, inflammation, hemorrhage, and edema of tissue, as well as the number of foci involved (Table 1). This grading was based on a previously published 4-grade scoring system ${ }^{12}$ with a grade of 5 (transmural necrosis) added.

\section{Statistical Analysis}

Statistical evaluation was performed with commercial statistical software (Stat for Windows, R.4.5; Stat Soft, Inc, Tulsa, Okla) with the Mann-Whitney U test or Kruskal-Wallis analysis of variance. Figure 1 shows results as mean $\pm \mathrm{SD}$.

\section{RESULTS}

\section{Stents and Implantation}

The stent in its nominal relaxed diameter of $6 \mathrm{~mm}$ and length of $30 \mathrm{~mm}$ exerts a radial expansion force of zero. According to the manufacturer's own measurements, the $12 \times 40$-mm stent lengthens by approximately $20 \%$ as its diameter constricts by $1 \mathrm{~mm}$, and the expansion force jumps to $106.3 \mathrm{~g} / \mathrm{cm}^{2}$. By maximal compression to half its original diameter, the stent achieves $150 \%$ of its original length, and the expansion force grows to $364.2 \mathrm{~g} / \mathrm{cm}^{2}$. During the first 5 weeks of in vitro degradation, the radial resistive forces persisted at around the initial values. At week 7, the radial force was about 2 thirds of the initial force, and in week 9 about half.

All stents were successfully delivered and deployed into the trachea with no technical problems. Loading duration of the stent into the delivery device improved with practice from 5 minutes to 1 minute, and the delivery of the stent into the tracheal lumen was managed quite easily. The original apnea duration of 200 seconds was reduced after the first 5 implantations to less than

TABLE 1. Grading system for tracheal tissue lesions: Tracheal damage score

\begin{tabular}{ll}
\hline Grade & Definition \\
\hline 0 & Normal histologic structure \\
1 & Mild damage: Mild epithelial hyperplasia; mild \\
& lymphoplasmacytic infiltration of lamina propria; \\
& fibrocartilaginous layer of normal morphology either \\
& adventitia; mild fibroplasia in lamina propria \\
& Moderate damage: Epithelium moderately hyperplastic with \\
& pronounced hyperplasia of goblet cells and moderate \\
& infiltration with heterophils; moderate lymphoplasmacytic \\
& infiltration of lamina propria; fibrocartilaginous layer of \\
& normal morphology either adventitia; moderate fibroplasia \\
& in lamina propria \\
& Severe and focal damage: Segmental necrosis of the \\
& epithelium and lamina propria; necrosis surrounded by \\
& moderate fibroplasia with scattered heterophils, \\
& lymphocytes, and plasma cells; fibrocartilaginous layer of \\
& normal morphology either adventitia \\
& Severe diffuse damage: Severe necrosis of tracheal mucosa \\
& affecting also fibrocartilaginous layer; severe accumulation \\
& of inflammatory cells and massive hemorrhage \\
& Transmural necrosis: Diffuse severe tissue necrosis of all the \\
& tracheal layers
\end{tabular}




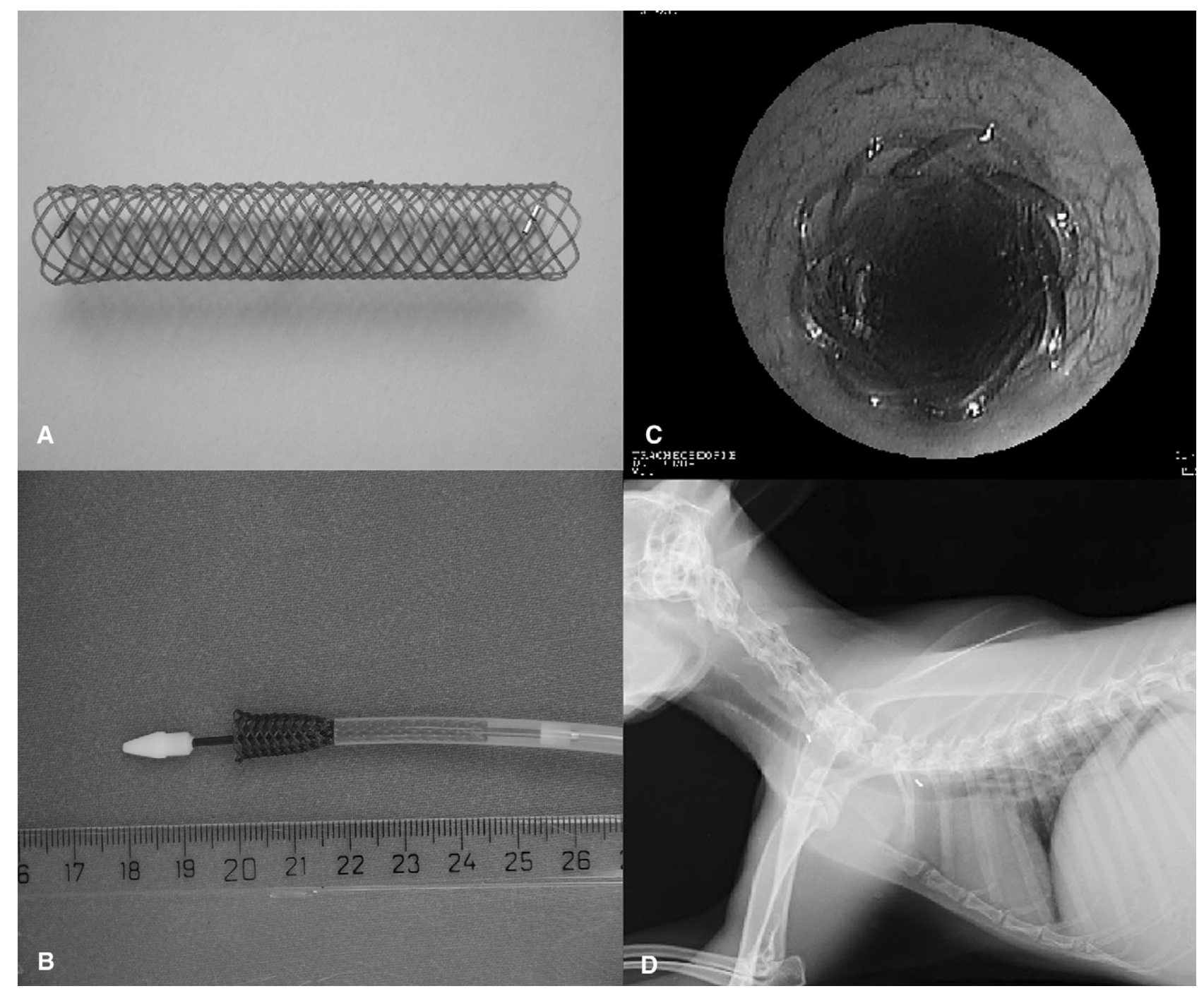

FIGURE 2. A, Biodegradable polydioxanone stent with 2 golden markers. B, Loaded stent and delivery system. C, Stent on bronchoscopy immediately after implantation. D, Fluoroscopic control of stent positioning.

100 seconds in the remaining cases. Neither stent migration nor stent fractures were observed on the control radiographs or bronchoscopies carried out after the procedure.

\section{Animal Study}

Mild clinical signs of respiratory distress were seen in the first 2 weeks after implantation. The difference in clinical impairment from week 2 to week 8 was statistically significant (Figure 2,C). The rabbits had shown expiratory and inspiratory stridor in this time, as well as mild to moderate mucopurulent nasal discharge. Higher intake of water and decreased appetite were also observed during this period. From week 5 onward, signs of respiratory distress progressively decreased, and during the final 2 weeks (from the 14th through the 15th week), only mild stridor was observed.

\section{Histopathologic Analysis}

Group W3 (killed third week after implantation; TDS range, 2-3). Macroscopically, the polydioxanone stent was seen to be fully intact at 3 weeks, without signs of inflammation (Figure 3, A). Microscopically, necrosis of the epithelium and lamina propria at the point of contact between the polydioxanone strand and the mucosa was seen. Necrosis was surrounded by moderate fibroplasia and scattered heterophils and lymphocytes (Figure 4, A). Epithelium between polydioxanone strands was moderately hyperplastic, with pronounced hyperplasia of goblet cells and mildly heterophil infiltration. Adjacent lamina propria was moderately infiltrated with heterophils and fibroblasts (Figure 4, $D$ ). The underlying fibrocartilaginous layer and adventitia were of normal morphology. The part of the trachea adjacent to the stent showed only mild lymphoplasmacytic infiltration of the lamina propria. Regional (cranial thoracic) 


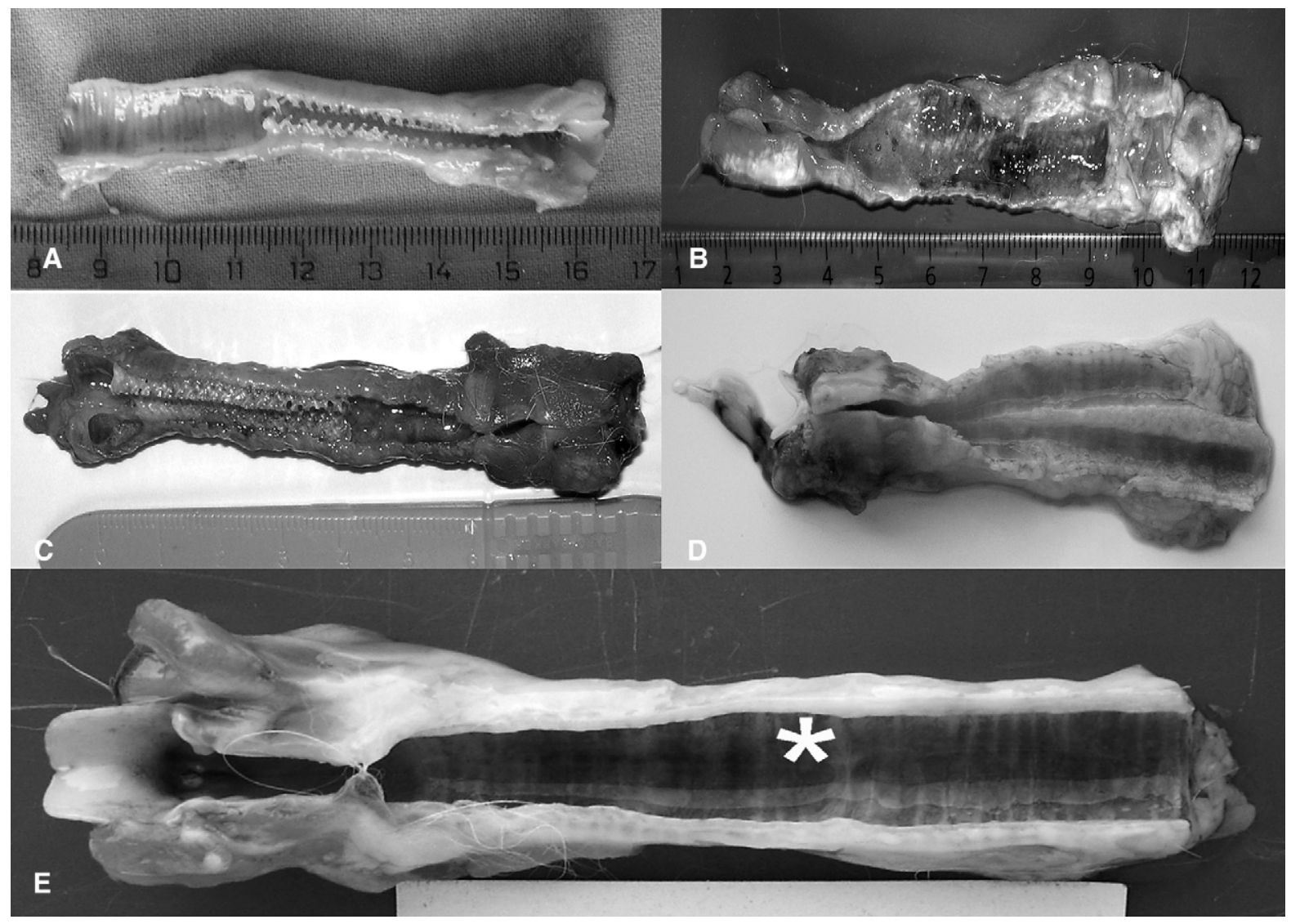

FIGURE 3. A, Rabbit trachea with stent in place 3 weeks after implantation. B, Trachea with severe inflammation and hemorrhages 4 weeks after implantation, stent removed. C, Discolored polydioxanone stent together with exudation and hyperplasia of mucosa 5 weeks after implantation. D, No stent is present in the trachea at 10 weeks after implantation; however, persistent inflammation and hyperplasia are present. E, Tracheal mucosa is slightly hyperemic with no signs of hyperplasia at 15 weeks after implantation. There is no more stent in the trachea, and there is only minimal scar tissue (asterisk).

lymph nodes were moderately enlarged, with signs of hyperplasia of the cortical lymphatic follicles (reactive hyperplasia).

Group W4 (killed fourth week after implantation; TDS range, 2-4). The stent was still intact at 4 weeks, and the mucosa was markedly hyperplastic and inflamed (Figure 3, B). Histologically, we observed severe purulent inflammatory infiltrate adherent to the mucosa, with large areas of desquamation of the epithelium (Figure 4, B). Fibroplasia in the lamina propria was moderate to severe, with mild to moderate angiogenesis. Tracheal tissue adjacent to the stent showed mild infiltration, with a moderate amount of lymphocytes and plasma cells in the lamina propria.

Group W5 (killed fifth week after implantation; TDS range, 3-4). At 5 weeks, discolored polydioxanone stent (Figure 3,C) was present macroscopically, as well as exudate and hyperplasia of mucosa. Microscopically, we observed marked fibroplasia around the stent strands and heterophilic infiltration of the epithelium and lamina propria, with masses of bacteria. In 1 animal, tracheal cartilage necrosis and replacement by fibroblast proliferation was observed. Hyperplastic fibrous tissue was moderately infiltrated with heterophils (Figure 4, E).

Group W10 (killed tenth week after implantation; TDS range, 2-3). At 10 weeks after implantation, we did not find any stent material in the trachea; however, inflammation and hyperplasia were observed (Figure $3, D$ ). The epithelium was hyperplastic, with mild to moderate infiltration of heterophils. There was marked goblet cell hyperplasia. Hyperplastic fibrous tissue of the lamina propria was moderately infiltrated with heterophils and markedly infiltrated with plasma cells and lymphocytes, especially perivascularly (Figure $4, C$ ). We did not see any cartilage damage.

Group W15 (killed fifteenth week after implantation; TDS range, 1-2). No stent material was present in any of the animals at 15 weeks after implantation. The mucosa was slightly hyperemic, but with no signs of hyperplasia. We noted only minimal scar tissue at the site of previous stent implantation (Figure 3, E, asterisk). 

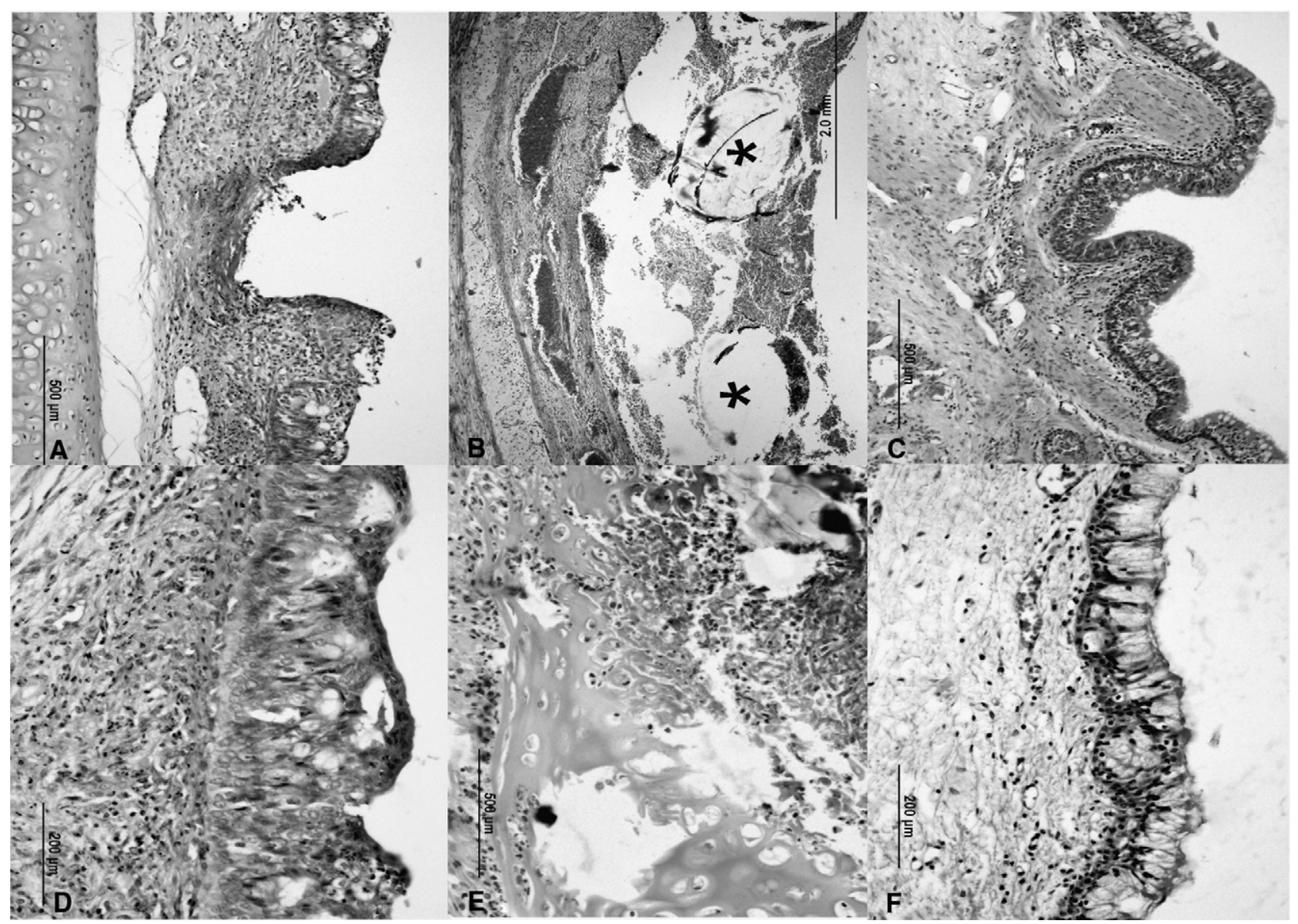

FIGURE 4. A, At 3 weeks after implantation, segmental necrosis of the tracheal mucosa at the previous site of the stent fiber, which has been removed (Hematoxylin-eosin staining; original magnification, $\times 100$ ). B, At 4 weeks after implantation, rich heterophilic infiltrate between stent strands (asterisks), desquamation of the epithelium, and congestion of mucosal blood vessels (original magnification, $\times 40$ ). C, At 10 weeks after implantation, hyperplastic epithelium with mild to moderate infiltration of heterophils, hyperplasia of goblet cells, and hyperplastic fibrous tissue of lamina propria markedly infiltrated with plasma cells and lymphocytes, especially perivascularly (original magnification, $\times 100$ ). D, At 3 weeks after implantation, moderate epithelial hyperplasia and mild infiltration of the epithelium with heterophils. There is also moderate fibroplasia in lamina propria and moderate infiltration with heterophils (original magnification $\times 400$ ). E, At 5 weeks after implantation, necrosis of tracheal cartilage with degenerated heterophils (original magnification, $\times 100$ ). F, At 15 weeks after implantation, marked goblet cell hyperplasia in the tracheal epithelium in the place of previous stent implantation with mild to moderate lymphoplasmacytic infiltration of the epithelium and lamina propria (original magnification, $\times 400$ ).

The epithelium was mildly infiltrated with lymphocytes and showed marked goblet cell hyperplasia (Figure $4, F$ ). In the locations of macroscopically obvious scar tissue, we observed hyperplastic fibrous tissue and mild lymphoplasmacytic infiltration. Mucosa adjacent to the previously implanted stent was of normal morphology.

\section{Semiquantitative Analysis of Tracheal Tissue Reaction and Statistical Analysis}

The TDS was highest in group W5 (Figure 2, A), with a mean damage grade of $3.53 \pm 0.51$. There were also significant differences between the control group and all the experimental groups (Mann-Whitney $\mathrm{U}$ test, all $P<.009$ ), as shown in Figure $2(B)$.

\section{DISCUSSION}

Various stenting options are available in the airway. Recently, Liu and colleagues ${ }^{19}$ summarized the evolution of biodegradable airway stenting and added their experience with the polycaprolactone airway stent in rabbits. In some cases, a quick absorption of the stent is desirable. Polydioxanone dissolves relatively quickly, and thus many complications do not have time to evolve. Bronchial stenosis in the anastomosis after lung transplant and benign tracheal stricture seems to be good indication for this type of stent, as well as tracheobronchial collapse as a result of malacia or external compression in children. The type of airway stenosis (localized, neoplastic, long-segment, or pulsatile) and patient age influence the result of biodegradable stenting. In the growing trachea, the remodeling toward airway 
patency is more likely, as it is in short, localized, benign stenosis. The durability of clinical results of biodegradable stenting in localized benign bronchial strictures was recently proved. The airway needed multiple stenting, but it then remained open as late as 50 months of follow-up. ${ }^{15}$

Common complications of airway stenting are mucosal oversecretion, formation of granulation tissue, and stent migration. ${ }^{20}$ We could reliably see hyperplasia of mucosal goblet cells, which most likely encouraged oversecretion and formation of granulation tissue. There was no stent migration, nor were there any stent remnants or debris. Disappearance of the stent could therefore theoretically be caused by removal of remnants through coughing, swallowing, and ingestion. The changes in radial force are important for migration prevention. High radial force holds the airway open better, and the stent shortens more predictably; however, it presents a certain risk of erosion. Stents with zero radial force will not erode, but they do have a tendency toward displacement. Clinical studies to compare tissue reactions to varying radial forces are needed.

Currently, there are other methods of description for the specific characteristics of self-expandable stents available. ${ }^{21}$ Chronic outward force describes the exertion of the stent to expand to its nominal diameter. Radial resistive force measures the resistance of the stent to constrictive forces. The opening forces of the ideal stent should be low, to avoid irritation and damage through damage of the stented wall. On the other hand, the resistance to forces closing the lumen should be high. ${ }^{22}$ In our study, chronic outward force was holding the stent in place (fully expanded stent outer diameter $6 \mathrm{~mm}$ vs inner diameter of rabbit trachea of approximately $5.6 \mathrm{~mm}$ ). This expansion force did not cause any permanent injury to the tracheal mucosa.

Our histopathologic findings revealed that all experimental groups had significantly different TDS values from that of the nonstented control group (Figure 1). During the first 2 weeks, we observed only mild clinical signs of respiratory distress. It seems that signs of obstruction increased when the reparative processes of respiratory mucosal hyperplasia started. In compliance with clinical signs, the most pronounced inflammation has been histologically observed at the 5th week after implantation. The inflammatory reaction and reparation caused the most marked restriction of the tracheal lumen in this period. In 1 animal, we observed tracheal cartilage necrosis. This was caused rather by the increased enzymatic activity of neutrophils rather than by the minimal mechanical compression. We were able to demonstrate both macroscopically and microscopically the regression of inflammatory reaction from week 5 to week 15. Observed hyperplasia of the tracheal mucosa has also been observed in rat models of tracheal stenting; however, that experiment only lasted 3 weeks. ${ }^{23}$

Microorganisms and inflammatory reaction speed up the loss of tensile strength of the polydioxanone stents. ${ }^{24}$
In vitro, polydioxanone has moderate initial tensile strength, and it loses approximately $30 \%$ of its initial strength in 3 weeks of degradation and $60 \%$ of its initial strength in 6 weeks. ${ }^{25}$ In our study, the stent disappeared between the 5th and 10th week after implantation. There were no signs of any residual polydioxanone fibers in the epithelium or lamina propria after 15 weeks. The amount of granulation tissue had already decreased by that point, with only minimal scar tissue and residual lymphoplasmacytic infiltration. One animal from the control group also had minimal inflammatory infiltration in the tracheal mucosa, most likely caused, however, by a reaction to environmental antigens.

\section{Limitations of the Study}

The size of the stents was chosen arbitrarily. Our oversizing of $15 \%$ may have created a bias, because the stents may have exerted different forces against the variously sized tracheal walls of the individual animals. It would probably be better to perform preoperative imaging and exact measurements of the individual tracheas to help choose stents of exactly the desired sizes.

Our result of normal airway stenting can neither confirm nor exclude an assumption that an injured or strictured airway would respond to a biodegradable stent with a greater degree of inflammation and a higher TDS. Only stenting of an experimentally created airway stricture could answer that question.

The histologic TDS evaluation was not blinded and was performed by a single observer (L.N.). This could create a potential bias, although any such bias should have been mitigated by the number of samples.

There were no in vitro tests performed on $6 \times 30$-mm polydioxanone stents. We instead adopted previous results from the manufacturer's testing of esophageal polydioxanone stents measuring $23 \mathrm{~mm} \times 18 \mathrm{~mm} \times 23 \mathrm{~mm} \times$ $60 \mathrm{~mm}$ (dog bone) and larger bronchial polydioxanone stents measuring $12 \mathrm{~mm} \times 40 \mathrm{~mm}$.

\section{CONCLUSIONS}

This rabbit airway model has shown the excellent biocompatibility of a new biodegradable polydioxanone stent. Clinical results suggest that although these stents cause temporary respiratory distress, they are well tolerated, support the tracheal wall, and completely disappear 10 weeks after implantation. Five weeks later (15 weeks after implantation), only mild lymphoplasmacytic inflammation and minimal residual scar tissue remained. We therefore can suggest polydioxanone stenting for future clinical studies in which complete stent degradation after temporary airway treatment is desirable.

We are indebted to Dr Ladislav Kalas for skilled assistance with picture processing. 


\section{References}

1. Chin CS, Litle V, Yun J, Weiser T, Swanson SJ. Airway stents. Ann Thorac Surg. 2008;85:S792-6.

2. Shin JH, Sung KB, Kim EY, Shin DH, Song HY. A rat tracheal model to investigate stent-induced tissue hyperplasia: a pilot study. J Vasc Interv Radiol. 2010; 21:1878-83.

3. Ricci M, Cohen GA, Roebuck D, Elliott MJ. Management of complex tracheoaortic fistula following neonatal tracheal reconstruction. Ann Thorac Surg. 2003; 75:1325-8.

4. Zilberman M, Nelson KD, Eberhart RC. Mechanical properties and in vitro degradation of bioresorbable fibers and expandable fiber-based stents. J Biomed Mater Res B Appl Biomater. 2005;74:792-9.

5. Ray JA, Doddi N, Regula D, Williams JA, Melveger A. Polydioxanone (PDS), a novel monofilament synthetic absorbable suture. Surg Gynecol Obstet. 1981; 153:497-507.

6. Sabino MA, Gonzalez S, Marquez L, Feijoo JL. Study of the hydrolytic degradation of polydioxanone PPDX. Polymer Degradation Stability. 2000;69:209-16.

7. Bünger CM, Grabow N, Sternberg K, Goosmann M, Schmitz KP, Kreutzer HJ, et al. A biodegradable stent based on poly(l-lactide) and poly(4hydroxybutyrate) for peripheral vascular application: preliminary experience in the pig. J Endovasc Ther. 2007;14:725-33.

8. Petrtýl J, Brůha L, Horák L, Zádorová Z, Dosedel Z, Laasch HU. Management of benign intrahepatic bile duct strictures: initial experience with polydioxanone biodegradable stents. Endoscopy. 2010;42(Suppl. 2):E89-90.

9. Dhar A, Topping JH, Johns E, O'Neill D. Biodegradable stents in refractory benign oesophageal strictures-first report of 4 patients from UK [abstract]. Gastrointest Endosc. 2009;69:AB254-5.

10. Kemppainen E, Talja M, Riihelä M, Pohjonen T, Törmälä P, Alftan O. A bioabsorbable urethral stent. An experimental study. Urol Res. 1993;21:235-8.

11. Saito Y, Minami M, Kobayashi M, Nakao Y, Omiya H, Imamura H, et al. New tubular bioabsorbable knitted airway stent: biocompatibility and mechanical strength. J Thorac Cardiovasc Surg. 2002;123:161-7.

12. Korpela A, Aarnio P, Sariola H, Törmälä P, Harjula A. Comparison of tissue reactions in the tracheal mucosa surrounding a bioabsorbable and silicone airway stents. Ann Thorac Surg. 1998;66:1772-6.
13. Korpela A, Aarnio P, Sariola H, Törmälä P, Harjula A. Bioabsorbable selfreinforced poly-L-lactide, metallic, and silicone stents in the management of experimental tracheal stenosis. Chest. 1999;115:490-5.

14. Saito Y, Minami K, Kaneda H, Okada T, Maniwa T, Araki Y, et al. New tubular bioabsorbable knitted airway stent: feasibility assessment for delivery and deployment in a dog model. Ann Thorac Surg. 2004;78: 1438-40.

15. Lischke R, Pozniak J, Vondrys D, Elliott MJ. Novel biodegradable stents in the treatment of bronchial stenosis after lung transplantation. Eur J Cardiothorac Surg. 2011;40:619-24.

16. Sabino AM, Gonzales S, Marquez L, Feijoo JL. Study of the hydrolytic degradation of polydioxanone PPDX. Polym Degrad Stab. 2000;69:209-16.

17. Loewen MS, Walner DL. Dimensions of rabbit subglottis and trachea. Lab Anim. 2001;35:253-6.

18. Lossef SV, Lutz RJ, Mundorf J, Barth KH. Comparison of mechanical deformation properties of metallic stents with use of stress-strain analysis. $J$ Vasc Interv Radiol. 1994;5:341-9.

19. Liu KS, Liu YH, Peng YJ, Liu SJ. Experimental absorbable stent permits airway remodeling. J Thorac Cardiovasc Surg. 2011;141:463-8.

20. Chin CS, Litle V, Yun J, Weiser T, Swanson SJ. Airway stents. Ann Thorac Surg. 2008;85:S792-6.

21. Duda SH, Wiskirchen J, Tepe G, Bitzer M, Kaulich TW, Stoeckel D, et al. Physical properties of endovascular stents: an experimental comparison. J Vasc Interv Radiol. 2000;11:645-54.

22. Duerig TW, Pelton AR, Stöckel D. The utility of superelasticity in medicine. Biomed Mater Eng. 1996;6:255-66.

23. Shin JH, Sung KB, Kim EY, Shin DH, Song HY. A rat tracheal model to investigate stent-induced tissue hyperplasia: a pilot study. J Vasc Interv Radiol. 2010; 21:1878-83.

24. Noppen M, Piérard D, Meysman M, Claes I, Vincken W. Bacterial colonization of central airways after stenting. Am J Respir Crit Care Med. 1999;160: 672-7.

25. Zilberman M, Nelson KD, Eberhart RC. Mechanical properties and in vitro degradation of bioresorbable fibers and expandable fiber-based stents. J Biomed Mater Res B Appl Biomater. 2005;74:792-9. 